\title{
NLRP3 in human glioma is correlated with increased WHO grade, and regulates cellular proliferation, apoptosis and metastasis via epithelial-mesenchymal transition and the PTEN/AKT signaling pathway
}

\author{
XIAO-FENG YIN*, QIONG ZHANG*, ZHUO-YU CHEN, HAI-FANG WANG, XIN LI, HONG-XIA WANG, \\ HAI-XIA LI, CHUN-MIN KANG, SHUAI CHU, KAI-FEI LI, YAO LI and YU-RONG QIU
}

Laboratory Medicine Center, Nanfang Hospital, Southern Medical University, Guangzhou, Guangdong 510515, P.R. China

Received December 21, 2017; Accepted June 8, 2018

DOI: 10.3892/ijo.2018.4480

\begin{abstract}
Glioma is the most prevalent and fatal primary tumor of the central nervous system in adults, while the development of effective therapeutic strategies in clinical practice remain a challenge. Nucleotide-binding domain leucine-rich family pyrin-containing 3 (NLRP3) has been reported to be associated with tumorigenesis and progression; however, its expression and function in human glioma remain unclear. The present study was designed to explore the biological role and potential mechanism of NLRP3 in human glioma. The results demonstrated that overexpression of NLRP3, apoptosis-associated speck-like protein containing a caspaserecruitment domain (ASC), caspase-1 and interleukin (IL)-1 $\beta$ protein in human glioma tissues were significantly correlated with higher World Health Organization grades. The in vitro biological experiments demonstrated that NLRP3 downregulation significantly inhibited the proliferation, migration and invasion, and promoted the apoptosis of SHG44 and A172 glioma cell lines. Furthermore, western blot assays revealed that the downregulation of NLRP3 significantly reduced the expression of ASC, caspase-1 and IL- $1 \beta$ protein. Furthermore, NLRP3 knockdown caused the inhibition of epithelial-mesenchymal transition (EMT), and inhibited the phosphorylation of AKT serine/threonine kinase (AKT) and phosphorylation of phosphatase and tensin homolog (PTEN). Consistently, the upregulation of NLRP3 significantly increased the expres-
\end{abstract}

Correspondence to: Professor Yu-Rong Qiu, Laboratory Medicine Center, Nanfang Hospital, Southern Medical University, 1838 Guangzhou Road North, Baiyun, Guangzhou, Guangdong 510515, P.R. China

E-mail: qiuyuronggz@126.com

*Contributed equally

Key words: NLR family pyrin domain containing 3, AKT serine/ threonine kinase, proliferation, apoptosis, migration, invasion, phosphatase and tensin homolog sion of ASC, caspase-1, IL-1 $\beta$ and phosphorylated-PTEN, promoted proliferation, migration, invasion and EMT, inhibited apoptosis, and activated the AKT signaling pathway. The data of the present study indicate that NLRP3 affects human glioma progression and metastasis through multiple pathways, including EMT and PTEN/AKT signaling pathway regulation, enhanced inflammasome activation, and undefined inflammasome-independent mechanisms. Understanding the biological effects of NLRP3 in human glioma and the underlying mechanisms may offer novel insights for the development of glioma clinical therapeutic strategies.

\section{Introduction}

Glioma is the most prevalent and fatal primary tumor of the central nervous system (CNS) in adults, accounting for $80 \%$ of all primary CNS tumors, with an annual incidence of $\sim 6$ cases/100,000 people in the United States (1). The poor outcomes for glioma patients primarily result from the malignant biological characteristics of glioma cells, including highly aggressive proliferative and invasive abilities $(1,2)$. While persistent efforts to investigate glioma molecular oncology have achieved accumulating progress, the detailed mechanisms remain to be elucidated. Developing effective treatment therapies against specific molecular targets in human glioma remain a significant challenge (3-5).

The nucleotide-binding domain leucine-rich family pyrincontaining 3 (NLRP3) inflammasome consists of the scaffold protein NLRP3, the adaptor protein apoptosis-associated specklike protein containing a caspase-recruitment domain (ASC) and caspase-1 $(6,7)$. Upon activation by endogenous pathogenand damage-associated molecular pattern molecules or exogenous irritants, the NLRP3 inflammasome is assembled, and acts as a platform for the maturation of the proinflammatory cytokines, including interleukin (IL)-1 $\beta$ and IL-18 (7-9). Subsequently this allows proinflammatory cytokine secretion, which promotes inflammation and immunity (7-9). The activation mechanism and function of the NLRP3 inflammasome during immuno-inflammatory responses have been widely investigated. However, accumulating studies have demonstrated that the NLRP3 inflammasome is associated with 
cancer progression (10-15). Notably, certain studies reported that NLRP3 functions in an unidentified inflammasome-independent manner, whereby NLRP3 may serve independently of the production of bioactive cleaved-caspase-1 and mature IL-1 $\beta(16,17)$. However, the in depth role of NLRP3 in glioma has not been well clarified.

In order to investigate the biological role of NLRP3 in glioma, the expression levels of NLRP3, as well as ASC, caspase- 1 and IL-1 $\beta$ protein in glioma tissues were analyzed using immunohistochemical staining. Subsequently, an NLRP3-specific small interfering RNA (si-NLRP3) was constructed to deplete NLRP3 expression levels, and a plasmid system [pIRES2-enhanced green fluorescent protein (EGFP)-NLRP3] was produced for upregulating NLRP3 protein in human glioma cell lines, SHG44 and A172. In order to determine the effects of NLRP3 on malignant cellular behaviors, in vitro biological function experiments and western blot assays were performed to determine alterations to epithelial-mesenchymal transition (EMT) components, and its potential molecular mechanism in the phosphatase and tensin homolog (PTEN)/AKT serine/threonine kinase (AKT) signaling pathway, providing a novel insight into the contributions of NLRP3 to human glioma malignancy.

\section{Materials and methods}

Human glioma tissue samples. A total of 39 human glioma tissues samples were obtained from patients who underwent surgery at Nanfang Hospital, Southern Medical University (Guangzhou, China) between October 2014 and October 2015. Written informed consent was obtained from all enrolled patients. The present study was approved by the Ethics Committee of Nanfang Hospital, Southern Medical University and was performed in accordance with The Declaration of Helsinki. The age of the patients (24 male and 15 female) ranged between 11 and 80 years, with a mean age of $42 \pm 11$ years. All specimens had been confirmed pathological diagnosis and classified according to the 2007 World Health Organization (WHO) classification criteria (18).

Immunohistochemical staining. The glioma specimens were fixed with $10 \%$ formalin at room temperature for $24 \mathrm{~h}$ and paraffin-embedded, and sectioned into 4- $\mu \mathrm{m}$ thick slices that were mounted onto microscope slides. Then, the slides were deparaffinized with xylene three times and rehydrated in a descending ethanol series (100, 95, 90, 80, 70\%). Antigen retrieval was performed by heating the samples for $15 \mathrm{~min}$ at $95^{\circ} \mathrm{C}$ in citrate buffer $(\mathrm{pH} 6.0)$, samples were then cooled at room temperature for $30 \mathrm{~min}$. The endogenous peroxidase activity was eliminated by $3 \%$ hydrogen peroxide in distilled water for $10 \mathrm{~min}$ at room temperature, then the slides were blocked by incubation with protein blocking solution (Dako; Agilent Technologies, Inc., Santa Clara, CA, USA) at room temperature for $30 \mathrm{~min}$. Subsequently, primary antibodies against NLRP3 (cat. no. ABF23; Merck KGaA, Darmstadt, Germany; 1:200; rabbit Ab), ASC (cat. no. ab128097; Abcam, Cambridge, MA, USA; 1:100; mouse mAb), caspase-1 (cat. no. 2225; Cell Signaling Technology, Inc., Danvers, MA, USA; 1:100; rabbit Ab), IL-1 $\beta$ (cat. no. 12242; Cell Signaling Technology, Inc.; 1:100; mouse mAb) were applied overnight at $4^{\circ} \mathrm{C}$. Following washing with PBS, Universal prediluted secondary antibody from the Vecstain ${ }^{\mathrm{TM}}$ ABC kit (cat. no. PK-6200; Vector Laboratories, Inc., Burlingame, CA, USA) was applied for $30 \mathrm{~min}$ at room temperature followed by washing with PBS. Then, the slides were incubated with the Vecstain $\mathrm{ABC}$ reagent for $30 \mathrm{~min}$ at room temperature, washed with PBS and then stained with 3,3'-diaminobenzidine using immunoperoxidase staining procedure (cat. no. SK-4105; Vector Laboratories, Inc.) according to the manufacturer's protocol. The sections were counterstained with hematoxylin solution (cat. no. C0107; Beyotime Institute of Technology, Haimen, China) according to the manufacturer's protocol. Images of the sliders were captured under a light microscope at x100 magnification.

Cell culture and transient transfection. Human glioma SHG44 and A172 cell lines, purchased from the Type Culture Collection of the Chinese Academy of Sciences (Shanghai, China), were cultured at $37^{\circ} \mathrm{C}$ with $5 \% \mathrm{CO}_{2}$ in Dulbecco's modified Eagle's medium (DMEM) (Gibco; Thermo Fisher Scientific, Inc., Waltham, MA, USA) supplemented with $10 \%$ fetal bovine serum (FBS; Invitrogen; Thermo Fisher Scientific, Inc.). Glioma cells were divided into five groups: Untransfected, si-negative control (NC), si-NLRP3, pIRES2-EGFP and pIRES2-EGFP-NLRP3 groups. To reduce endogenous NLRP3 expression, glioma cells of 70-80\% confluence were transfected with $1 \mu \mathrm{g} /$ well NLRP3-specific si-NLRP3 (cat. no. siB1261155342; sequence, 5'-GGTGTTGGAATTAGAC AAC-3') or si-NC (cat. no. siN05815122147; sequence, 5'-AAG CCUCGAAAUAUCUCCU-3') (Guangzhou RiboBio Co., Ltd., Guangzhou, China) dissolved in a transfection medium mixture of Opti-MEM (Gibco; Thermo Fisher Scientific, Inc.) and Lipofectamine 3000 (Invitrogen; Thermo Fisher Scientific, Inc.) at a working concentration of $50 \mathrm{nM}$ according to the manufacturer's protocol. In parallel, for overexpression of NLRP3 in glioma cells, transfection with plasmid vectors pIRES2-EGFP-NLRP3 or the negative control pIRES2-EGFP [ $2 \mu \mathrm{g} /$ well; both from Obio Technology (Shanghai) Corporation, Ltd., Shanghai, China] was performed according to the manufacturer's protocol. The untransfected group was only cultured with a transfection medium mixture of Opti-MEM and Lipofectamine 3000. After $6 \mathrm{~h}$ of transfection, the transfection medium was replaced and cells were cultured for another $24 \mathrm{~h}$ in DMEM with 10\% FBS. The pIRES2-EGFP-NLRP3 groups were imaged at X100 magnification using an inverted phase contrast fluorescent microscope to assess GFP fluorescence. For confirmation of NLRP3 knockdown or overexpression efficiency, the cells were harvested and analyzed for NLRP3 protein expression using western blotting. The transfected glioma cells were subjected for in vitro functional experiments or western blot analysis experiments detecting molecular markers as described below.

Western blot analysis. Cells were extracted using ice-cold radio immunoprecipitation assay lysis buffer (Beyotime Institute of Biotechnology). Protein concentration in the cell lysate was determined using a bicinchoninic acid assay (Beyotime Institute of Biotechnology). A total of $50 \mu \mathrm{g}$ protein/lane were loaded and separated using 10\% SDS-PAGE, then transferred to polyvinylidene fluoride membranes (Merck KGaA), and 
blocked in PBS/Tween-20 containing 5\% bovine serum albumin (EMD Millipore, Billerica, MA, USA) for $2 \mathrm{~h}$ at room temperature. Subsequently, the membranes were incubated overnight at $4^{\circ} \mathrm{C}$ with primary antibodies against the following: NLRP3 (cat. no. ABF23; Sigma-Aldrich; Merck KGaA; 1:2,000; rabbit Ab), ASC (cat. no. ab128097; Abcam; 1:500; mouse mAb), caspase-1 (cat. no. 2225; 1:1,000; rabbit Ab), IL-1 $\beta$ (cat. no. 12242; 1:1,000; mouse mAb), E-cadherin (cat. no. 3195), zonula occluden-1 (ZO-1) (cat. no. 8193), claudin-1 (cat. no. 13255), vimentin (cat. no. 5741), N-cadherin (cat. no. 13116), Snail-1 (cat. no. 3879), AKT (cat. no. 4691), phosphorylated (p)-AKT (Ser473) (cat. no. 4060), p-AKT (Thr308)

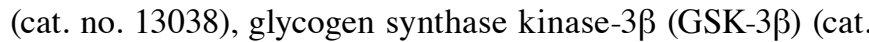
no. 12456), p-GSK-3 $\beta$ (Ser9) (cat. no. 5558), p-PTEN (Ser380) (cat. no. 9551), PTEN (cat. no. 9188) and $\beta$-actin (cat. no. 8457) (all from Cell Signaling Technology, Inc.; 1:1,000; rabbit Ab). The membranes were then incubated with the goat anti-rabbit or goat anti-mouse $\mathrm{IgG} /$ horseradish peroxidase-conjugated secondary antibody (anti-rabbit cat. no. bs-0295G-hrp; antimouse cat. no. bs-0296G-hrp; both 1:5,000; BIOSS, Beijing, China) for $1 \mathrm{~h}$ at room temperature. To visualize protein bands, ECL system (Bio-Rad Laboratories, Inc., Hercules, CA, USA) was used. The intensity of protein bands was analyzed using ImageJ version 1.6.0 software (National Institutes of Health, Bethesda, MD, USA) and normalized by $\beta$-actin.

Colony formation assay. Glioma cells were seeded in 6-well plates at 100 cells/well. Two weeks later, cell colonies were fixed with $4 \%$ paraformaldehyde for $30 \mathrm{~min}$ at room temperature and stained with $0.1 \%$ crystal violet for $30 \mathrm{~min}$ at room temperature. The numbers of colonies with $>50$ cells were counted under a light microscope and the images were captured using a digital camera.

Cell counting kit (CCK)-8 assay. Cell viability was detected using a Cell Counting kit-8 assay (Dojindo Molecular Technologies, Inc., Kumamoto, Japan). The glioma cells were seeded into 96 -well plates $\left(2 \times 10^{3}\right.$ cells $\left./ 200 \mu \mathrm{l} / \mathrm{well}\right)$ and cultured at $37^{\circ} \mathrm{C}$, and $10 \mu \mathrm{l} \mathrm{CCK}-8$ solution was added at 8,24 , 48 and $72 \mathrm{~h}$. Following incubation for $2 \mathrm{~h}$, the absorbance at $450 \mathrm{~nm}$ was measured.

5-ethynyl-2'-deoxyuridine (EdU) cell proliferation assay. Cell proliferation rates were measured using an EdU cell proliferation assay kit (cat. no. C10310; Guangzhou RiboBio Co., Ltd.) according to the manufacturer's protocol. Briefly, glioma cells $\left(2 \times 10^{4}\right.$ cells/well) were cultured in 24 -well plates for $24 \mathrm{~h}$. Then, $10 \mu \mathrm{M}$ of EdU and Apollo 643 staining for red fluorescence was added to each well, and the cells were cultured for an additional $2 \mathrm{~h}$. Next, the cells were fixed with $4 \%$ formaldehyde for $30 \mathrm{~min}$ at room temperature. Subsequently, the cells were stained with Hoechst 33342 for $30 \mathrm{~min}$ at room temperature, and visualized in blue fluorescence using a fluorescent microscope at x100 and x200 magnifications. The proliferating cells (EdU-positive cells in red) and total cells (Hoechst 33342-positive cells in blue) were counted using Image-Pro Plus 6.0 software (Media Cybernetics, Inc., Bethesda, MD, USA). The ratio of EdU positive cells to total Hoechst 33342 positive cells was used as cell proliferation rate.
Quantification of cell apoptosis using flow cytometric assays. Cells were harvested and stained using the Annexin V-APC/7-AAD kit (BD Biosciences, San Jose, CA, USA) for quantification of cell apoptosis according to the manufacturer's protocol. Cell detection and data analysis were performed on a fluorescent activated cell sorting caliber flow cytometer (FACScan; BD Biosciences) with CellQuest Pro software (version 5.1; BD Biosciences).

Wound healing assay. For the wound healing assays, $2 \times 10^{5}$ glioma cells were seeded on 6-well plates and cultured to $90 \%$ confluence. The confluent cell monolayer was scratched with a sterile pipette tip. The suspended cells were washed with non-serum DMEM. The rate of wound closure was monitored by measuring the ratio of the distance of the wound at $0 \mathrm{~h}$ and $24 \mathrm{~h}$ under an inverted microscope with a digital camera in five fields of view at x100 magnification and quantified using Adobe Photoshop (version 7.0; Adobe Systems, Inc., San Jose, CA, USA). Each experiment was performed in triplicate.

Cell migration and invasion assays. Cell migration and invasion assays were performed using 24-well Transwell chambers with $8-\mu \mathrm{m}$ pore size polycarbonate membrane (Corning, Cambridge, MA, USA). The transfected cells were cultured for $48 \mathrm{~h}$ and then $5 \times 10^{4}$ cells were seeded on the top side of the membrane without Matrigel for the cell migration assay or pre-coated with Matrigel (BD Biosciences) for the cell invasion assay. A total of $500 \mu \mathrm{l}$ DMEM containing $20 \%$ FBS was added to the lower chambers. Following incubation in $12 \mathrm{~h}$ for the migration assay or $48 \mathrm{~h}$ for the invasion assay, cells inside the upper chamber were removed with cottons swabs. Migrated and invaded glioma cells attached to the lower membrane surface were fixed with $75 \%$ methanol for $30 \mathrm{~min}$ at room temperature, and then stained for $30 \mathrm{~min}$ with crystal violet at room temperature. Five random fields of view at X100 magnification were counted in each well under a light microscope and expressed as the mean number of migrated or invaded cells. Three independent assays were performed.

Statistical analysis. Data are presented as the mean \pm standard deviation. Statistical analyses were performed with SPSS software version 13.0 (SPSS, Inc., Chicago, IL, USA). Spearman's correlation coefficient was used to assess the correlation between protein expression levels and glioma WHO grades. Student's t-tests were used to compare data variances between two groups, and one-way analysis of variance with the Dunnett's post hoc test was used to compare difference among multiple groups. $\mathrm{P}<0.05$ (two-tailed) was considered to indicate a statistically significant difference.

\section{Results}

High expression levels of NLRP3, ASC, caspase-1 and IL-1 $\beta$ are correlated with glioma WHO grade. NLRP3, ASC, caspase-1 and IL-1 $\beta$ protein compose the NLRP3 inflammasome. Immunohistochemical detection of human glioma tissue sections revealed that NLRP3, ASC, caspase- 1 and IL-1 $\beta$ protein expression levels were all upregulated in high-grade glioma (WHO III and IV) tissue samples compared with in low-grade glioma (WHO I and II) tissue, as presented in 
A
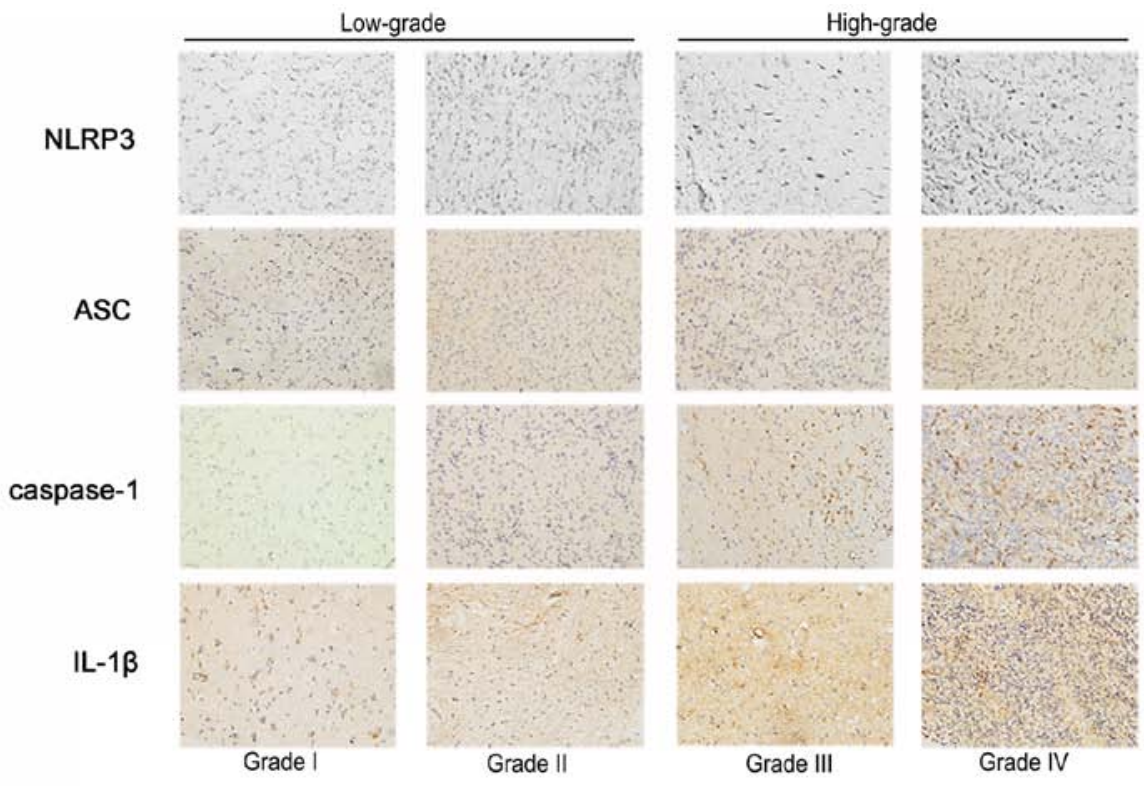

B
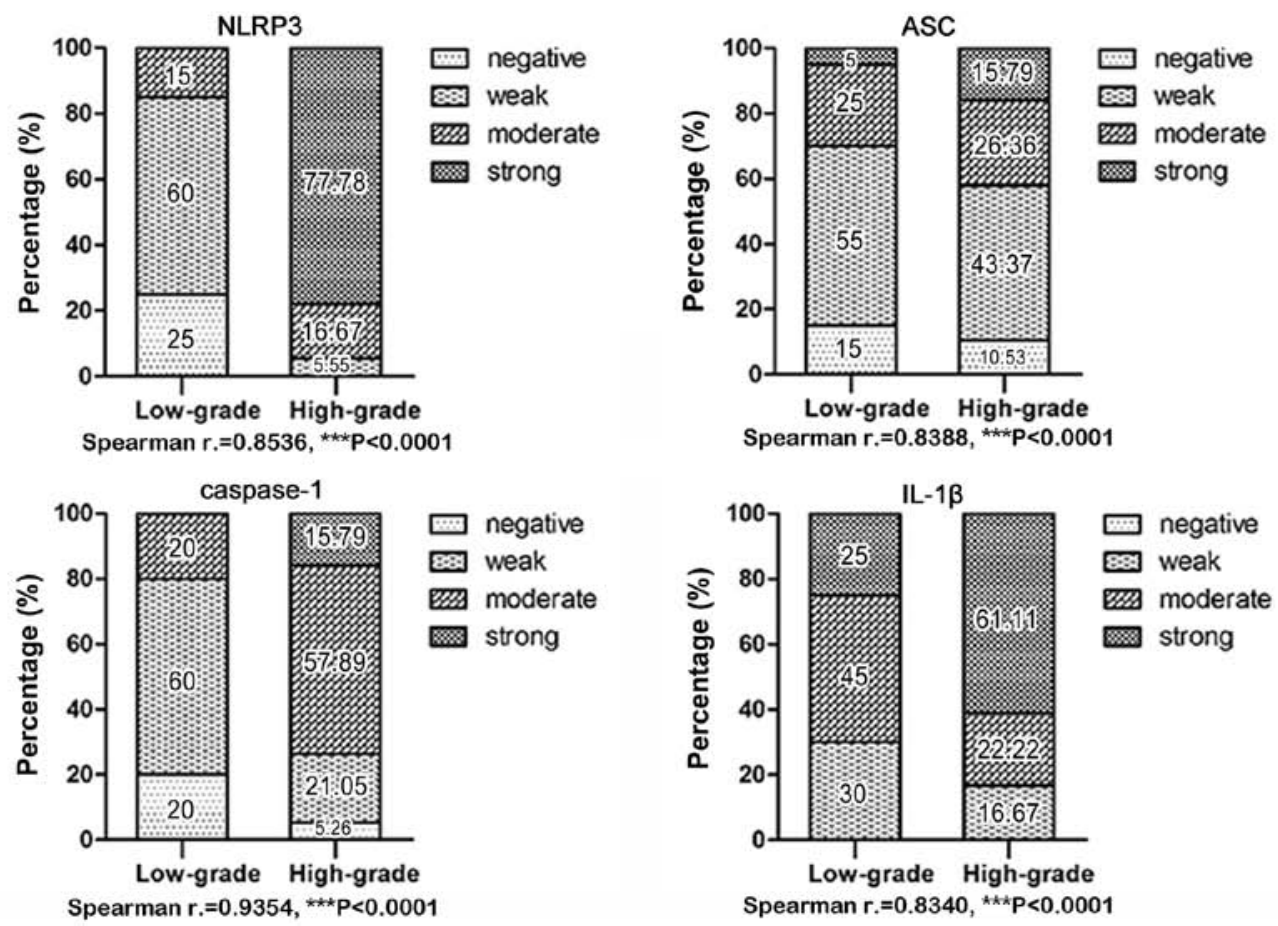

Figure 1. NLRP3, ASC, caspase-1 and IL-1 $\beta$ tissue expression in low-grade glioma (WHO I and II) and high-grade glioma was analyzed by immunohistochemical staining. (A) Representative images are shown at magnification, x100. (B) Statistical analyses were performed to determine whether the expression levels of NLRP3, ASC, caspase-1 and IL-1 $\beta$ in human glioma tissue correlated with histological grades. NLRP3, NLR family pyrin domain containing 3; ASC, apoptosis-associated speck-like protein containing a caspase-recruitment domain; IL, interleukin.

Fig. 1A. Statistical analysis confirmed significantly positive correlations between NLRP3, ASC, caspase- 1 and IL- $1 \beta$ protein expression levels, and the histological grades of human glioma (Fig. 1B), indicating an important role for NLRP3 in glioma malignancy.

Verification of NLRP3 downregulation and overexpression efficiencies in glioma cells. To evaluate the role of NLRP3 in the malignant biological properties of glioma, siRNA-NLRP3 and the plasmid vector pIRES2-EGFP-NLRP3 were constructed to downregulate and upregulate NLRP3 expression, respectively, in glioma cell lines SHG44 and A172. The plasmid vector pIRES2-EGFP-NLRP3 exhibited a transfection efficiency of $>80 \%$ in SHG44 and A172 glioma cells as indicated by GFP fluorescence (Fig. 2A). Western blot analysis verified a significant reduction in NLRP3 protein levels following the transfection of si-NLRP3 compared with si-NC (Fig. 2B and C). Furthermore, pIRES2-EGFP-NLRP3 transfection resulted in a significant increase in NLRP3 expression compared with the corresponding untransfected and pIRES2-EGFP control groups. These results confirmed the efficiency of si-NLRP3 and pIRES2-EGFP-NLRP3 for 

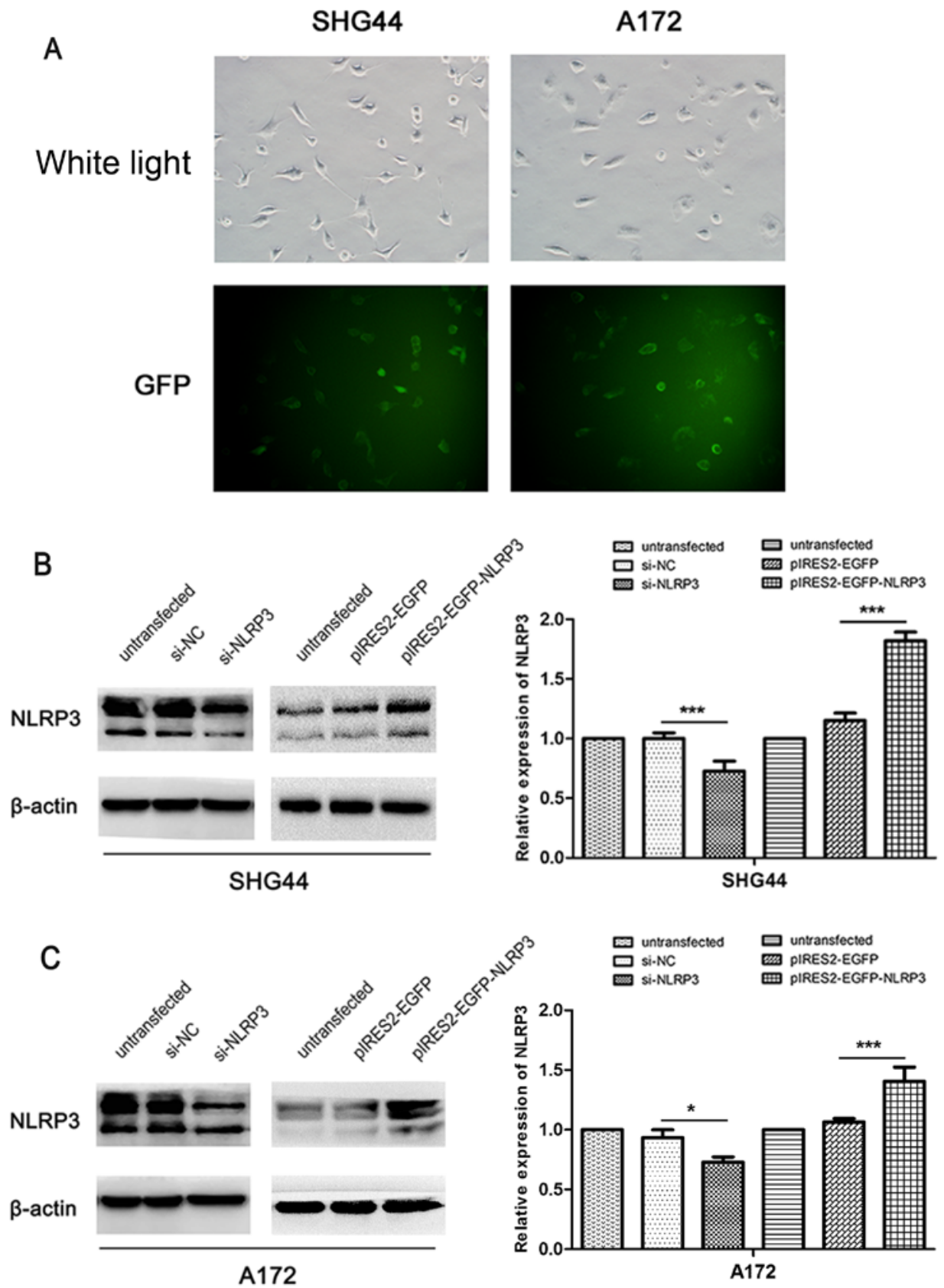

Figure 2. Identification of the efficiency of NLRP3 downregulation and overexpression in glioma cell lines, SHG44 and A172. (A) The transfection efficiency of plasmid vector was indicated using bright field and GFP (magnification, x100); (B) Western blot analysis detected the downregulation and overexpression efficiency of NLRP3 at protein levels. The intensity of protein bands was measured and the values are presented as the mean \pm standard deviation $(\mathrm{n}=3$ ). ${ }^{*} \mathrm{P}<0.05$ and ${ }^{* * * *} \mathrm{P}<0.001$. NLRP3, NLR family pyrin domain containing 3; GFP, green fluorescent protein; NC, negative control; EGFP, enhanced green fluorescent protein.

use in the NLRP3 downregulation or overexpression in vitro functional experiments in glioma cells.

Facilitative effects of NLRP3 on the proliferation of glioma cells. The effect of NLRP3 on cell proliferation was assessed using colony formation, CCK-8 and EdU assays. In glioma SHG44 and A172 cell lines, downregulation of NLRP3 significantly suppressed colony formation, whereas overexpression of NLRP3 using pIRES2-EGFP-NLRP3 significantly promoted colony formation compared with the corresponding untransfected and negative control groups (Fig. 3A). Then, the growth effects of NLRP3 on human glioma cell lines were evaluated using CCK-8 assays. The si-NLRP3 groups demonstrated a significant reduction in cell viability compared with si-NC group, while NLRP3 overexpression significantly increased the viabilities of human glioma cell lines compared with the pIRES2-EGFP control groups in a time-dependent manner (Fig. 3B). Furthermore, similar effects on cell proliferation were confirmed using an EdU assay. The ratio of EdU-positive cells to total cell nuclei was used to determine the cell proliferation rate. The results revealed that the cell proliferation rate in the si-NLRP3 group was significantly reduced compared with the scramble si-NC group (Fig. 3C). Furthermore, pIRES2-EGFP-NLRP3 transfection significantly increased 
A
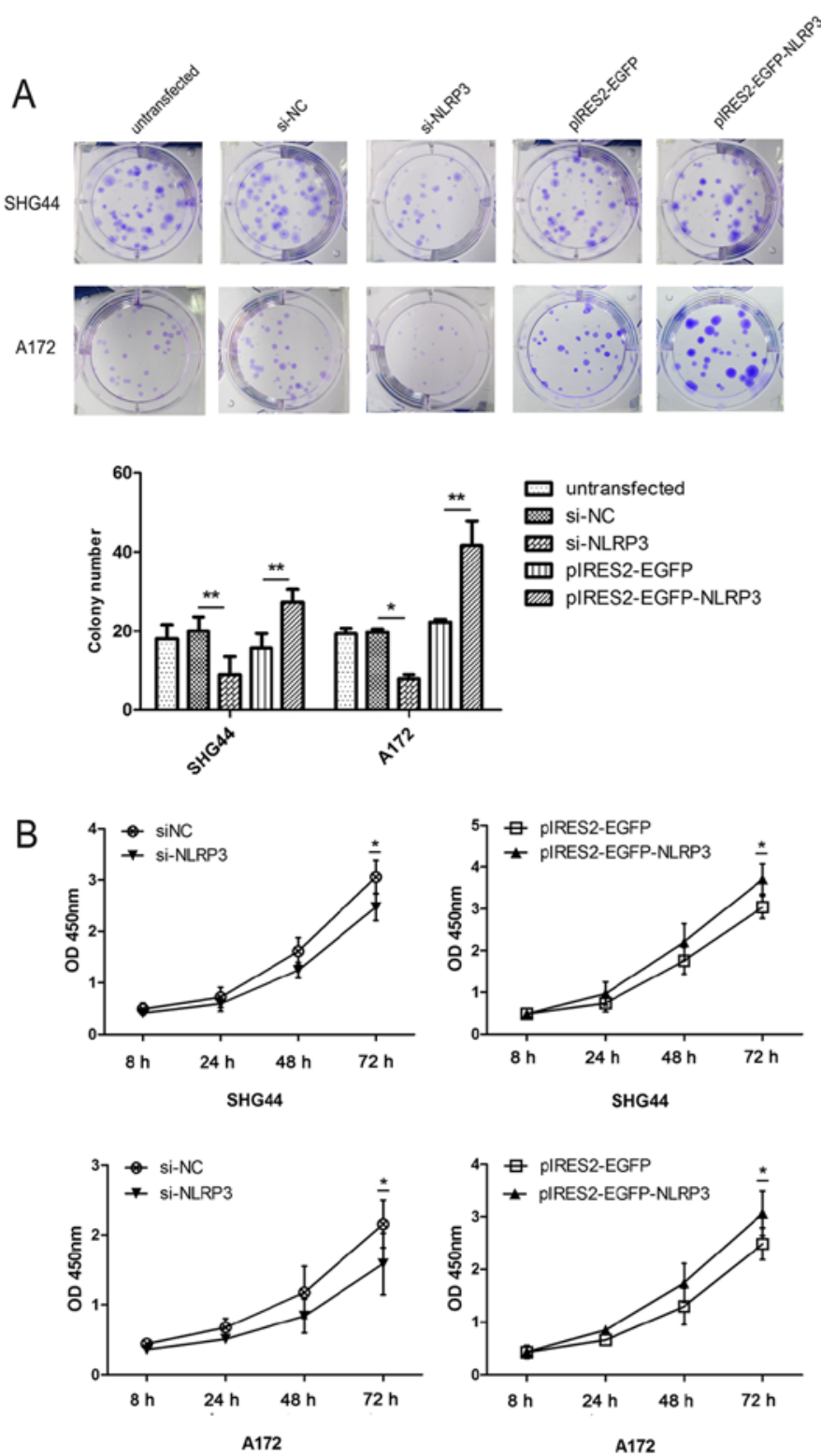
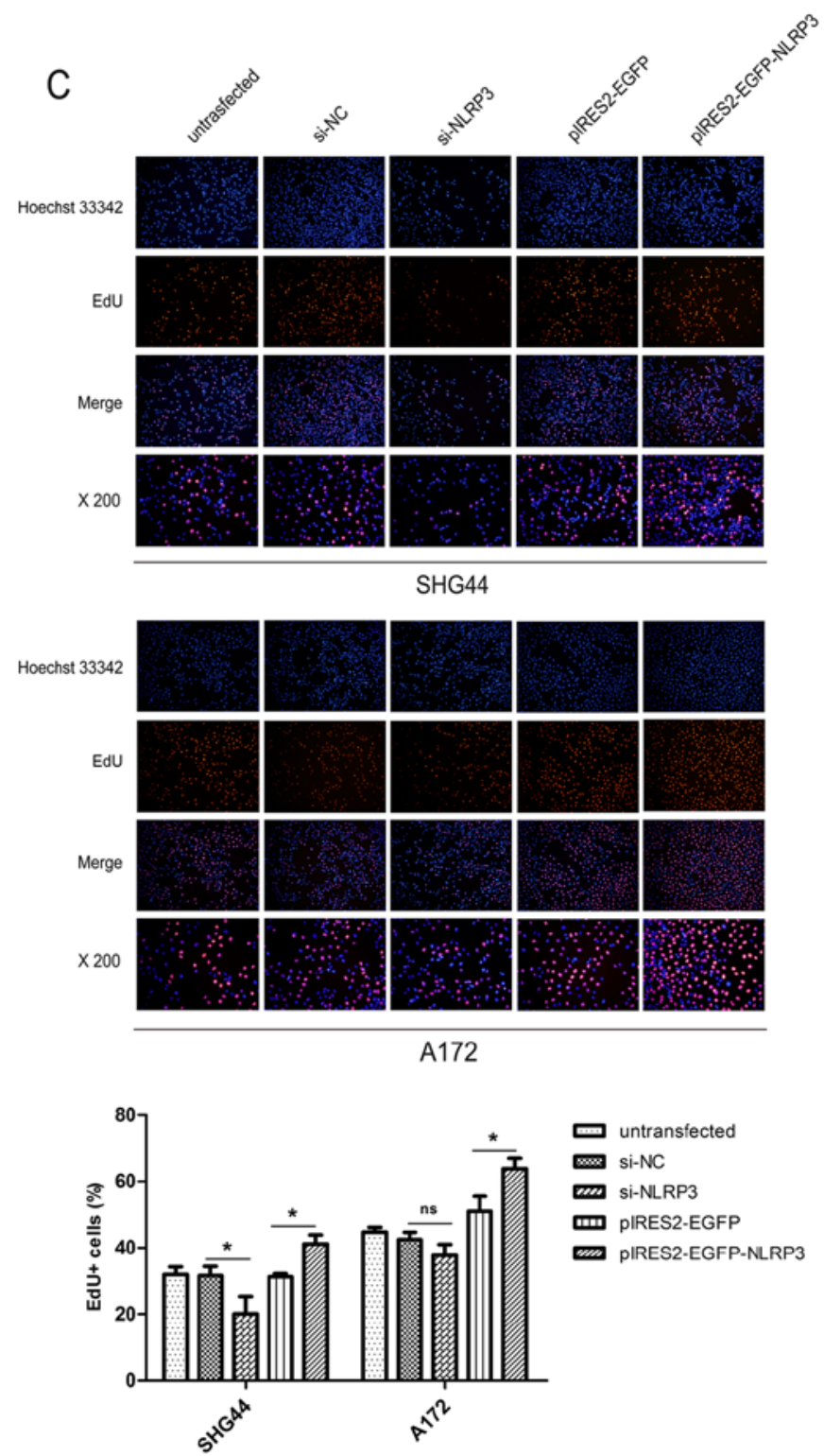

Figure 3. Facilitative effect of NLRP3 on the proliferation of SHG44 and A172 glioma cells. (A) The effect of NLRP3 on glioma cell viability was assessed using a colony formation assay. (B) A Cell Counting Kit-8 assay was used to measure cell viability in untransfected and transfected glioma cells. (C) An EdU assay was used to evaluate the proliferation rate of glioma cells. Representative images are shown at magnification, $\mathrm{x} 100$ (A) and $\mathrm{x} 200$ (C). Values are presented as the mean \pm standard deviation $(n=3)$. ${ }^{*} \mathrm{P}<0.05$ and ${ }^{* *} \mathrm{P}<0.01$. NLRP3, NLR family pyrin domain containing 3 ; EdU, 5 -ethynyl-2'-deoxyuridine; $\mathrm{NC}$, negative control; EGFP, enhanced green fluorescent protein; OD, optical density.

the cell proliferation rate compared with pIRES2-EGFP group in SHG44 and A172 glioma cells (Fig. 3C).

Inhibitory effects of NLRP3 on glioma cell apoptosis. To further investigate the effect of NLRP3 on the cell apoptosis, Annexin V-APC and 7-AAD staining of human glioma cells was performed, and the apoptosis rate of each group was measured by flow cytometry after $48 \mathrm{~h}$ of transfection. Downregulation of NLRP3 by si-NLRP3 significantly induced apoptosis of SHG44 and A172glioma cell lines compared with the si-NC group (Fig. 4). Following overexpression of NLRP3, the apoptosis rates of pIRES2-EGFP-NLRP3 groups were significantly reduced compared with that of the pIRES2-EGFPgroupsin SHG44 and A172 glioma cells (Fig. 4).
NLRP3 promotes glioma cell migration and invasion. To explore the effect of NLRP3 on glioma cell migration and invasion, wound healing assays, and Transwell migration and invasion assays were performed. The wound healing assays demonstrated that the migratory ability of glioma cells was significantly suppressed following transfection of si-NLRP3 and pIRES2-EGFP-NLRP3 significantly accelerated the wound closure compared with the corresponding negative control groups (Fig. 5A). In the Transwell migration assays, the number of migrated glioma cells in thesi-NLRP3 group was significantly decreased compared with untransfected group and si-NC groups (Fig. 5B). Accordingly, pIRES2-EGFP-NLRP3 transfection significantly increased cell migratory abilities in SHG44 and A172 glioma cell lines (Fig. 5B). The results of the Transwell invasion assays revealed that, compared with 

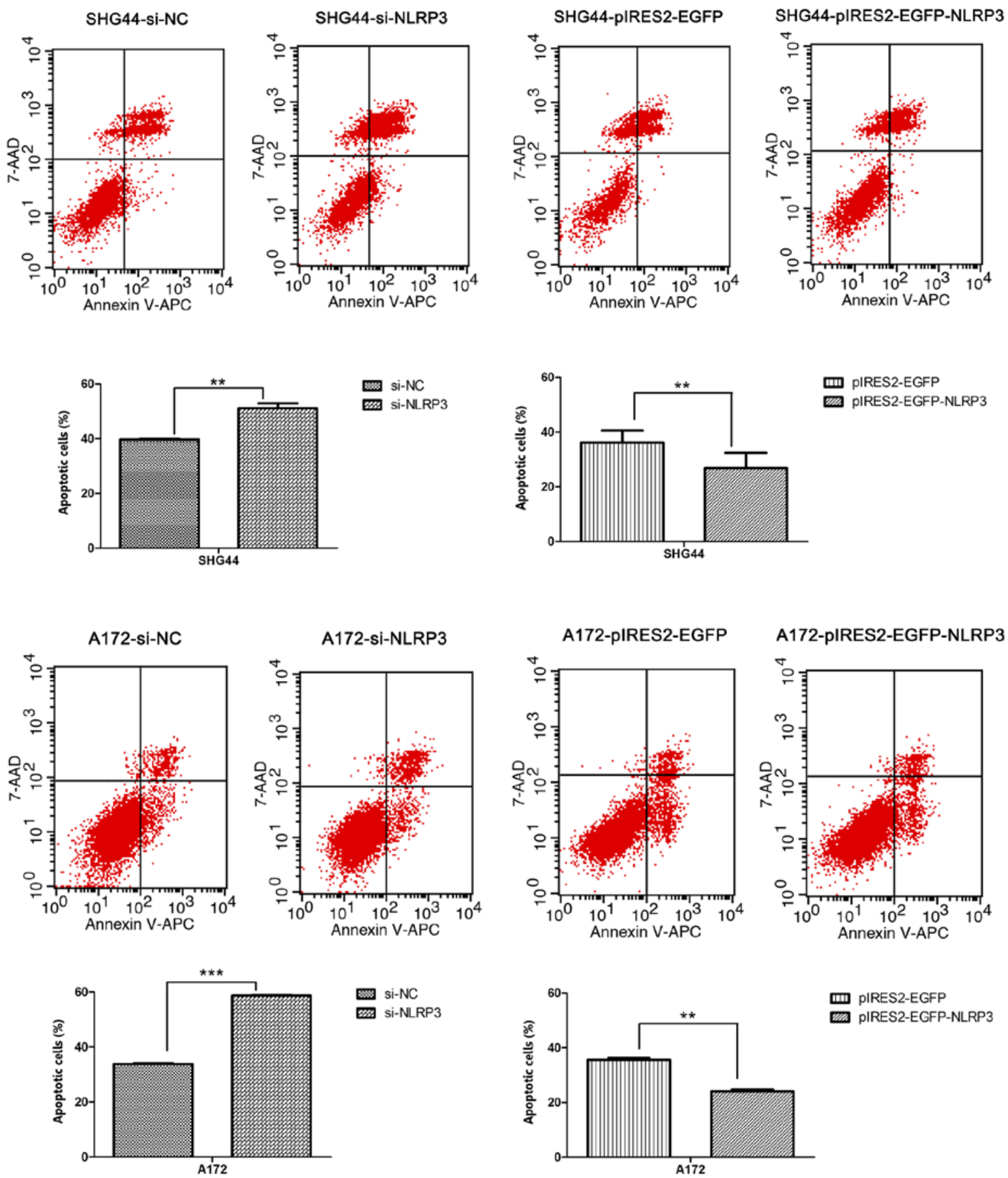

Figure 4. Effect of NLRP3 on SHG44 and A172 glioma cell apoptosis. The apoptotic glioma cells labeled with Annexin V-APC and 7-AAD were detected by flow cytometry. Values of apoptosis rate were expressed as the mean \pm standard deviation $(\mathrm{n}=3)$. ${ }^{* *} \mathrm{P}<0.01$ and ${ }^{* * *} \mathrm{P}<0.001$. A representative apoptosis plot from three experiments performed is shown. NLRP3, NLR family pyrin domain containing 3; APC, allophycocyanin; 7-AAD, 7-Aminoactinomycin D; NC, negative control; EGFP, enhanced green fluorescent protein.

the untransfected and si-NC groups, si-NLRP3 significantly reduced the number of glioma cells that invaded through the Matrigel-coated membrane at $48 \mathrm{~h}$, whereas pIRES2EGFP-NLRP3 significantly promoted the invasiveness of glioma cells (Fig. 5C).

Regulatory effects of NLRP3 on intracellular inflammasome activation, EMT and the AKT pathway in glioma cells. Western blot analysis was performed on molecules of the NLRP3 inflammasome complex, ASC, pro-caspase-1 and pro-IL-1 $\beta$, and molecules that indicate inflammasome activation, cleaved-caspase-1 (p20) and mature IL-1 $\beta$ (17 kDa) in SHG44 and A172 glioma cell lines. The protein bands of pro-caspase-1 and cleaved-caspase-1 (p20) were visualized using the same primary antibodies against caspase- 1 at 50 and $25 \mathrm{kDa}$, respectively. Similarly, pro-IL-1 $\beta$ and mature IL-1 $\beta$ were visualized using the same primary antibodies against IL-1 $\beta$ at 35 and $17 \mathrm{kDa}$, respectively. Compared with the untransfected and si-NC groups, si-NLRP3 transfection significantly decreased the protein expression of all molecules of the 

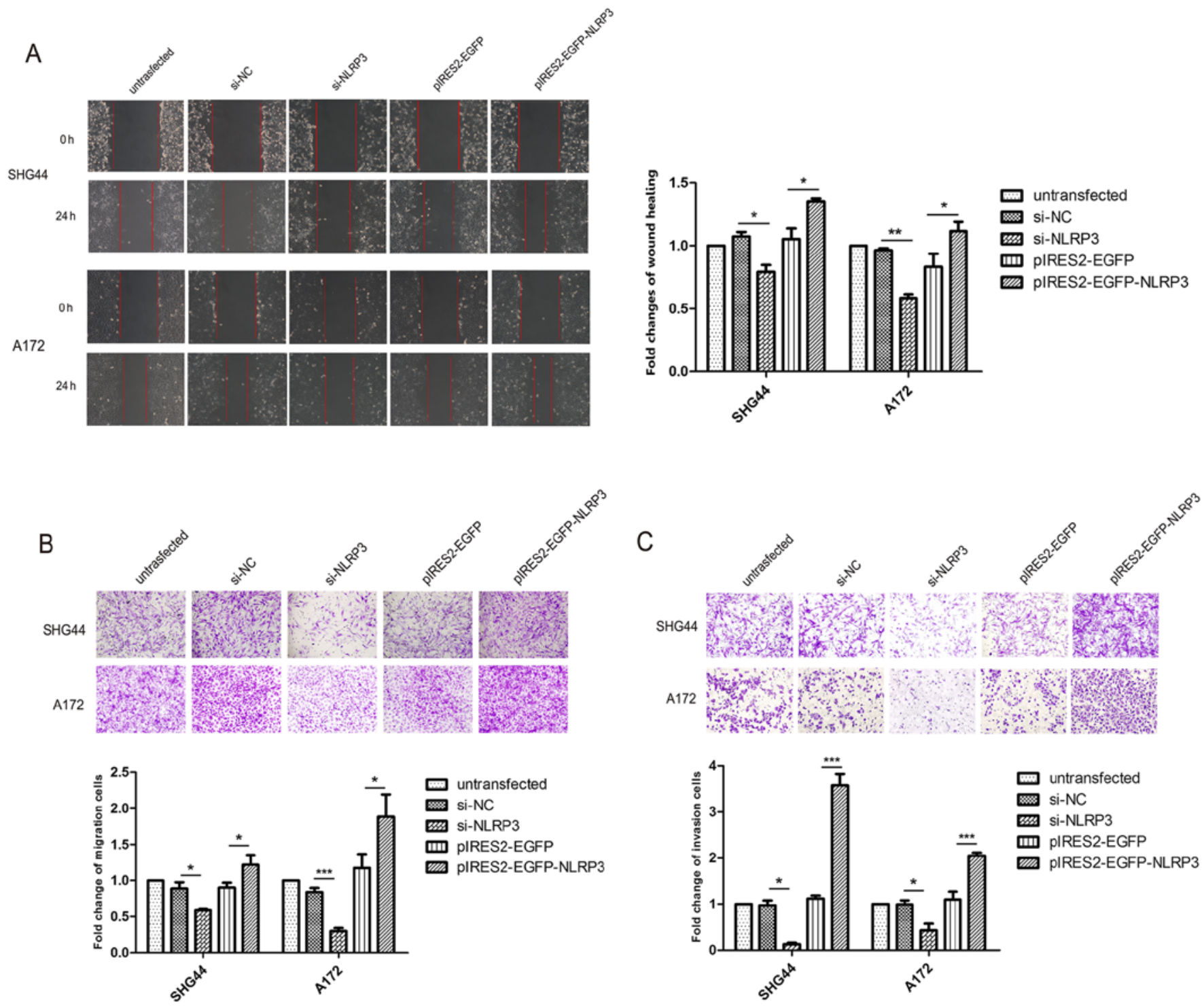

Figure 5. Effect of NLRP3 on promoting migration and invasion in SHG44 and A172 human glioma cells. (A) The effect of NLRP3 on glioma cells migratory ability was assessed using wound healing assays. The rate of wound closure was monitored by measuring the ratio of the distance of the wound at 0 and $24 \mathrm{~h}$. (B) The effect of NLRP3 on glioma cells migratory ability was detected using Transwell migration assays. (C) The effects of NLRP3 on glioma cellular invasion ability were detected using Transwell invasion assays. Representative images of wound healing, Transwell migration and invasion assays from three independent experiments are presented. Values are expressed as the mean \pm standard deviation $(n=3) .{ }^{*} \mathrm{P}<0.05,{ }^{* * *} \mathrm{P}<0.01$ and ${ }^{* * * *} \mathrm{P}<0.001$. NLRP3, NLR family pyrin domain containing 3; NC, negative control; EGFP, enhanced green fluorescent protein.

NLRP3 inflammasome complex, and cleaved-caspase-1 and mature IL-1 $\beta$. Furthermore, NLRP3 overexpression significantly increased the expression levels of all 6 inflammasome complex-associated markers compared with the untransfected and pIRES2-EGFP negative control groups (Fig. 6).

As indicated by the aforementioned results, NLRP3 demonstrated an intimate association with tumor malignances involving apoptosis, proliferation, migration and invasion in human glioma cells. EMT is widely regarded as a major contributor to increased tumor metastasis, resulting in a higher capacity of cellular migration and invasion $(19,20)$. Furthermore, cellular junctions serve an essential role in structural connection, which may be involved in cancer metastasis (21). The major components of tight junctions include ZO-1) and claudin-1. To further explore the facilitative effect of NLRP3 on the migration and invasion of glioma cells, western blot analysis assays were performed on molecules associated with EMT and cellular tight junctions. The results revealed that si-NLRP3 significantly downregulated the expression levels of mesenchymal proteins $(\mathrm{N}$-cadherin and vimentin) and EMT-associated transcription factor Snail-1, while it upregulated the expression of epithelial markers and cellular tight junctions proteins (E-cadherin, ZO-1 and claudin-1) compared with the untransfected and si-NC groups. Compared with the untransfected and control vector groups, the pIRES2-EGFP-NLRP3 group significantly reduced E-cadherin, ZO-1 and claudin-1 protein expression, and increased the expression of $\mathrm{N}$-cadherin, vimentin and snail-1 (Fig. 7).

The AKT signaling pathway has been associated with the development of glioma malignances via its inhibitory effect on apoptosis, as well as its promoter roles on proliferation, 

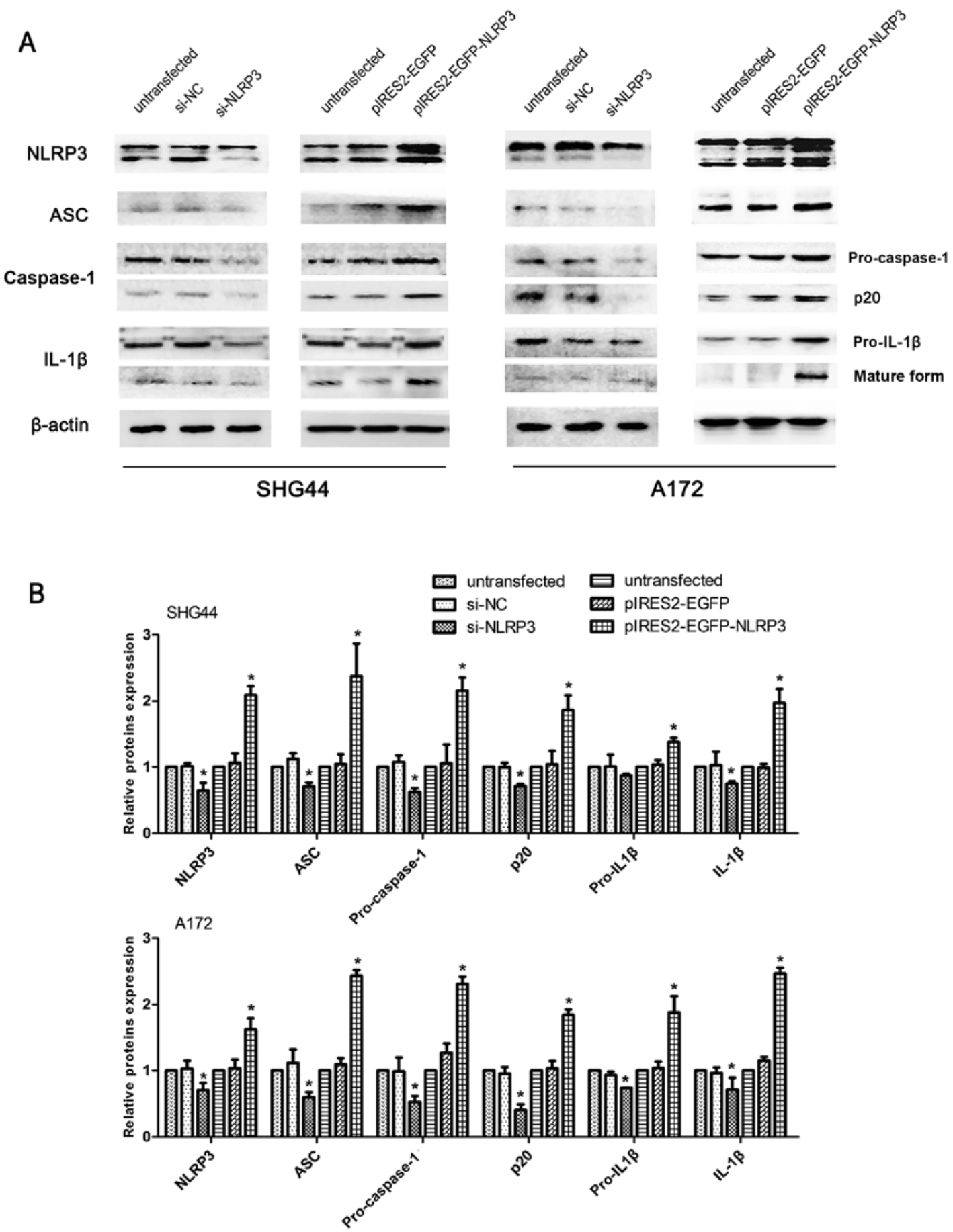

Figure 6. Regulatory effects of NLRP3 on intracellular inflammasome activation in glioma cells. (A) The effect of NLRP3 on altering the expression of molecules involved in the construction of inflammasome complex and its activation. The expression levels of ASC, caspase-1, pro-IL-1 $\beta$ and the molecules that indicate inflammasome activation, including cleaved-caspase-1 (p20) and mature IL-1 $\beta$ (17 kDa) were assessed by western blot analysis. (B) The intensity of protein bands was measured and the values as the mean \pm standard deviation $(n=3)$. ${ }^{*} \mathrm{P}<0.05$. NLRP3, NLR family pyrin domain containing 3 ; ASC, apoptosisassociated speck-like protein containing a caspase-recruitment domain; IL, interleukin; NC, negative control; EGFP, enhanced green fluorescent protein.

migration and invasion (22,23). As indicated in Fig. 8 , p-AKT (Ser473), p-AKT (Thr308) and p-GSK3 $\beta$ (Ser9) expression levels were significantly reduced in the si-NLRP3 group, and significantly increased in NLRP3-overexpressing glioma cells compared with untransfected groups and negative control groups. Notably, no marked differences in total AKT and GSK $3 \beta$ protein levels were noted in the knockdown and overexpression experiments. Furthermore, the si-NLRP3 groups reduced p-PTEN levels, while overexpression of
NLRP3 significantly attenuated the phosphorylation of PTEN with no marked differences observed on total PTEN protein expression in glioma cell lines (Fig. 8).

\section{Discussion}

The expression and function of the NLRP3 has been previously investigated in inflammatory and autoimmune diseases $(6,7)$. Notably, there is an increasing amount of evidence indicating 

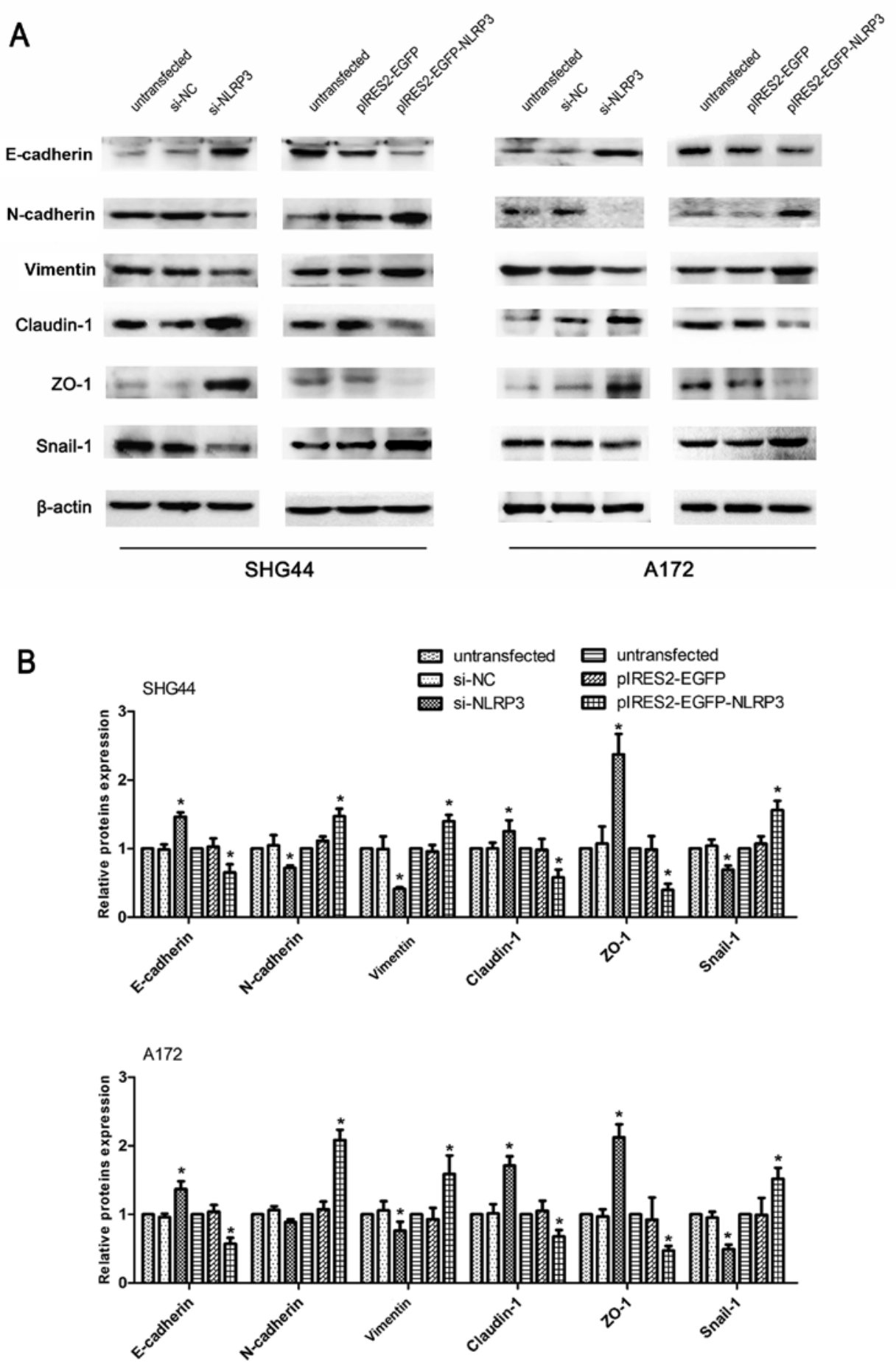

Figure 7. Regulatory effects of NLRP3 on molecules involved in EMT in glioma cells. (A) The changes in EMT-associated proteins or transcriptional factors include E-cadherin, N-cadherin, vimentin, claudin-1, ZO-1 and snail-1 in glioma cell lines SHG44 and A172 were assessed by western blot analysis. (B) The intensity of protein bands was measured and the values are presented as the mean \pm standard deviation $(n=3)$. ${ }^{*}<<0.05$. NLRP3, NLR family pyrin domain containing 3; NC, negative control; EGFP, enhanced green fluorescent protein; EMT, epithelial-mesenchymal transition; ZO-1, zonulaoccluden-1.

an important role of NLRP3 in the carcinogenesis of various tumors; however, the results appear to be inconsistent among different types of cancer (10-12,15,24-26). NLRP3 tissue expression and its function in glioma remain unclear.

In the present study, upregulated protein expression of NLRP3, ASC, caspase-1 and IL-1 $\beta$ in human glioma tissue was significantly associated with higher WHO grades as confirmed using immunohistochemical assays. These results provided a foundation for further NLRP3 functional studies and suggesting a promising role for NLRP3 in glioma progression. Furthermore, western blot assays demonstrated that NLRP3 significantly affected the expression of other constructive molecules of the inflammasome complex, including ASC, caspase- 1 and pro-IL-1 $\beta$, as well as inflammasome-activated status markers, cleaved-caspase1 and mature IL-1 $\beta$. These finding implied that the overexpression of NLRP3 in human glioma may elevate the expression of other inflammasome complex proteins and the cellular inflammasome-activated 

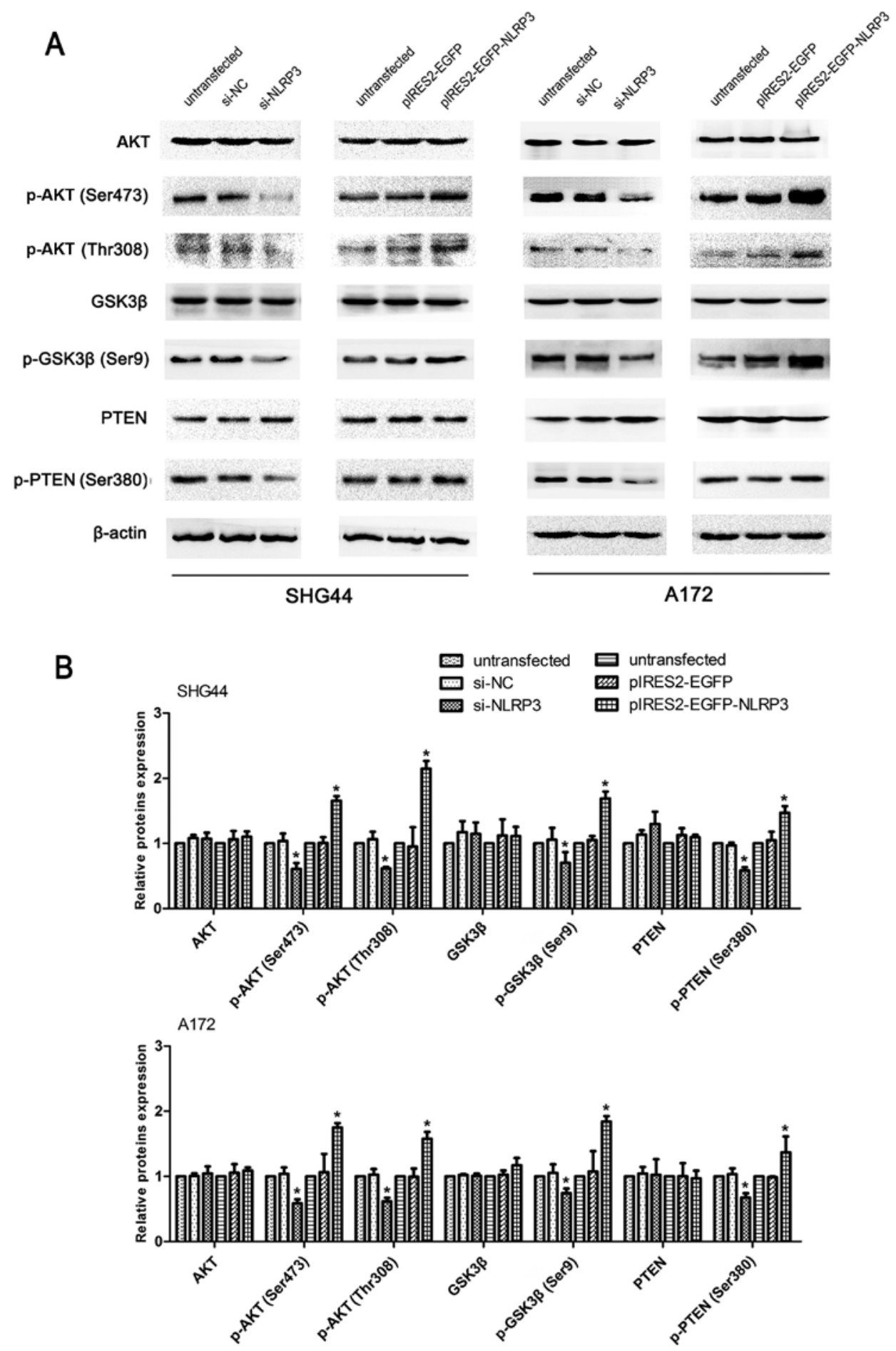

Figure 8. Regulatory effects of NLRP3 on the PTEN/AKT signaling pathway in glioma cells. (A) Western blotting was used to determine the level of proteins associated with PTEN/AKT signaling pathway, including total AKT, p-AKT (Ser473), p-AKT (Thr308), GSK3 $\beta$, p-GSK3 $\beta$ (Ser9), and its regulators p-PTEN (Ser380) and total PTEN. (B) The intensity of protein bands was measured and the values are presented as the mean \pm standard deviation ( $\mathrm{n}=3$ ). ${ }^{*} \mathrm{P}<0.05$. NLRP3, NLR family pyrin domain containing 3; NC, negative control; EGFP, enhanced green fluorescent protein; AKT serine/threonine kinase; GSK3 $\beta$, glycogen synthase kinase-3 $\beta$; PTEN, phosphatase and tensin homolog.

status. Subsequently, the in vitro biological function experiments and western blot assays identified that NLRP3 participated in the regulation of glioma cellular proliferation, apoptosis, migration, invasion, EMT and the PTEN/AKT signaling pathway.

A previous study reported that the assembly and activation of the NLRP3 inflammasome complex, constructed of NLRP3, ASC, caspase-1 and pro-IL-1 $\beta$ proteins, functions as a negative regulator in the carcinogenesis of colitis-associated cancer (27). In hepatocellular carcinoma (HCC), the NLRP3 inflammasome complex was identified to be downregulated and its upregulation induced by the 17 $\beta$-estradiol/estrogen receptor $\beta /$ mitogen-activated protein kinase signaling pathway attributes to inhibition of HCC cell malignancy $(14,24)$. However, Wang et al (17) reported that NLRP3 expression, but not inflammasome activation, is required for the EMT process 
in colorectal cancer cells through regulation of Snail-1. It was also suggested that NLRP3 contributes to renal fibrosis by promoting transforming growth factor- $\beta$ signaling and $\mathrm{R}$-Smad activation, independent of inflammasome activation and cleaved-caspase-1 production in renal tubular epithelial cells (16). In lung cancer, NLRP3 mediates the release of IL-1 $\beta$ and IL-18 through a caspase-1-dependent or independent pathway (28). NLRP3 also enhances the proliferation and migration of A549 cells, the activation of phosphorylation of AKT and the expression of Snail-1, while downregulating the expression of E-cadherin (28). The contradiction in the aforementioned studies suggests that NLRP3 may affect tumorigenesis and progression independent of its involvement in the inflammasome complex.

As one of the most important effectors of the NLRP3 inflammasome upon activation, IL-1 $\beta$ is an essential cytokine in the glioma inflammatory microenvironment (29), and considered a potent enhancer of glioma proliferation and metastasis (30-32). Tarassishin et al (33) reported that human glioma cells produce IL-1 $\beta$ upon highly sensitive NLRP3 inflammasome activation; however, in human normal astrocytes, NLRP3 inflammasome activation and mature IL-1 $\beta$ protein production are suppressed almost entirely, indicating that the ability of glioma cells to activate the NLRP3 inflammasome and produce IL-1 $\beta$ may lead to the development of an aggressively oncogenetic phenotype (33).

Numerous signaling pathways are involved in regulating the malignant anti-apoptotic and proliferative characteristics of glioma, of these molecular mechanisms the AKT signaling pathway is particularly important (34-36). The mutation/deletion of the tumor suppressor PTEN is an inhibitive regulator of the AKT signaling pathway $(37,38)$. Furthermore, EMT is considered one of the most important processes that contribute to glioma progression and metastasis $(19,20)$. Consistent with the aforementioned studies, the observations in the present study identified that NLRP3 functioned as a promoter of glioma cell migration and invasion by increasing Snail-1 expression, subsequently inducing EMT. Additionally, NLRP3 alleviated cellular apoptosis, promoted cell proliferation upon activation of the AKT signaling pathway and resulted in a reduction in PTEN phosphorylation.

A previous study suggested that the induction of p-PTEN induces a loss of PTEN activity, resulting in the activation of the AKT signaling pathway (39). Mizushina et al (40) demonstrated that NLRP3 ${ }^{-1-}$ mice exhibited diminished signal transducer and activator of transcription 3 (STAT3) expression in an inflammasome-independent way. STAT3 is a transcription factor that regulates various genes, including polo like kinase 1 (PLK1), a phosphatase of PTEN that leads to its inactivation and blockade of AKT signaling pathway $(41,42)$. In addition, the upregulation of STAT3 enhances Snail expression (43), and increased Snail-1 expression was observed in the NLRP3 overexpression model used in the present study. Thus, we hypothesized that the NLRP3/STAT3/PLK1 signaling axis is involved in the regulation of NLRP3 on the PTEN/AKT signaling pathway. In parallel, reduced $\mathrm{Smad} 2$ phosphorylation combined with less Smad2/3 translocation have been reported in NLRP3deficient B61pr mice (44). Furthermore, reduced Smad2/3 phosphorylation results in decreased binding with Smad4 and impaired translocation of the Smad2/3/4 complex into the nucleus $(45,46)$. The Smad complex has been confirmed as a direct binding site-targeted PTEN genetic promoter, which subsequently regulates PTEN transcription $(45,46)$. There appears to be multiple pathways and complex crosstalk connecting NLRP3 to PTEN/AKT. The results of the present study indicate that NLRP3 regulates glioma malignancy through enhanced inflammasome activation, and undefined inflammasome-independent mechanisms that target EMT and the AKT signaling pathway by inducing PTEN phosphorylation. The in depth regulatory mechanism between NLRP3 and PTEN remains to be explored, and will be the focus of our future investigations.

To the best of our knowledge, this is the first study to investigate the association between NLRP3 protein expression and the WHO grades of human glioma. The findings of the present study suggest that NLRP3 may function as a tumor promoter, and that the aberrant activation of the AKT signaling pathway and EMT process caused by NLRP3 upregulation may provide a novel insight into the underlying mechanism of NLRP3 in glioma malignancy.

\section{Acknowledgements}

The authors would like to thank Professor Songtao Qi,Professor Yawei Liu and Dr Guozhong Yi (Department of Neurosurgery, Nanfang Hospital, Southern Medical University) for providing experimental suggestion and technical aid in immunohistochemical analysis of human glioma tissue samples.

\section{Funding}

The present study was supported by grants from the Guangdong Natural Science Foundation (grant no. 2016A030313525), Science and Technology Program of Guangzhou (grant no. 201607010015) and Presidential Foundation of Nanfang Hospital, Southern Medical University (grant no. 2017C024). The funders had no role in study design, data collection and analysis, decision to publish, or preparation of the manuscript.

\section{Availability of data and materials}

The datasets used and/or analyzed during the current study are available from the corresponding author on reasonable request.

\section{Authors' contributions}

YRQ and XFY conceived and designed the study; XFY, QZ, ZYC, SC, KFL and YL performed the experiments; XFY, QZ, HFW, XL, HXW, HXL and CMK contributed to the experimental data collection and analysis. XFY and QZ wrote the manuscript. All authors read and approved the final manuscript.

\section{Ethics approval and consent to participate}

The Ethics Committee of the Nanfang Hospital, Southern Medical University approved the experimental protocols, and all patients provided written informed consent for the use of their tissues in the present study. 


\section{Patient consent for publication}

Not applicable.

\section{Competing interests}

The authors declare that they have no competing interests.

\section{References}

1. Wen PY and Reardon DA: Neuro-oncology in 2015: Progress in glioma diagnosis, classification and treatment. Nat Rev Neurol 12: 69-70, 2016.

2. Mao K, Lei D, Zhang H and You C: MicroRNA-485 inhibits malignant biological behaviour of glioblastoma cells by directly targeting PAK4. Int J Oncol 51: 1521-1532, 2017

3. Omuro A and DeAngelis LM: Glioblastoma and other malignant gliomas: A clinical review. JAMA 310: 1842-1850, 2013.

4. Olar A and Sulman EP: Molecular markers in low-grade gliomatoward tumor reclassification. Semin Radiat Oncol 25: 155-163, 2015.

5. Christofides A, Kosmopoulos M and Piperi C: Pathophysiological mechanisms regulated by cytokines in gliomas. Cytokine 71 : 377-384, 2015

6. Strowig T,Henao-Mejia J,Elinav E and Flavell R: Inflammasomes in health and disease. Nature 481: 278-286, 2012.

7. Lamkanfi $M$ and Dixit VM: Mechanisms and functions of inflammasomes. Cell 157: 1013-1022, 2014

8. Haneklaus M, O'Neill LA and Coll RC: Modulatory mechanisms controlling the NLRP3 inflammasome in inflammation: Recent developments. Curr Opin Immunol 25: 40-45, 2013.

9. He Y, Hara H and Núñez G: Mechanism and regulation of NLRP3 inflammasome activation. Trends Biochem Sci 41: 1012-1021, 2016.

10. Kent A and Blander JM: Nod-like receptors: Key molecular switches in the conundrum of cancer. Front Immunol 5: 185, 2014

11. Terlizzi M, Casolaro V,Pinto A and Sorrentino R: Inflammasome: Cancer's friend or foe? Pharmacol Ther 143: 24-33, 2014

12. Paugh SW, Bonten EJ, Savic D, Ramsey LB, Thierfelder WE, Gurung P, Malireddi RK, Actis M, Mayasundari A, Min J, et al: NALP3 inflammasome upregulation and CASP1 cleavage of the glucocorticoid receptor cause glucocorticoid resistance in leukemia cells. Nat Genet 47: 607-614, 2015.

13. Schneider SL, Ross AL and Grichnik JM: Do inflammatory pathways drive melanomagenesis? Exp Dermatol 24: 86-90, 2015

14. Wei Q, Guo P, Mu K, Zhang Y, Zhao W, Huai W, Qiu Y, Li T, Ma X, Liu Y, et al: Estrogen suppresses hepatocellular carcinoma cells through ER $\beta$-mediated upregulation of the NLRP3 inflammasome. Lab Invest 95: 804-816, 2015.

15. Sharma N and Jha S: NLR-regulated pathways in cancer: Opportunities and obstacles for therapeutic interventions. Cel Mol Life Sci 73: 1741-1764, 2016.

16. Wang W, Wang X, Chun J, Vilaysane A, Clark S, French G, Bracey NA, Trpkov K, Bonni S, Duff HJ, et al: Inflammasomeindependent NLRP3 augments TGF- $\beta$ signaling in kidney epithelium. J Immunol 190: 1239-1249, 2013.

17. Wang $\mathrm{H}$, Wang $\mathrm{Y}, \mathrm{Du} \mathrm{Q}, \mathrm{Lu} \mathrm{P}, \mathrm{Fan} \mathrm{H}, \mathrm{Lu} \mathrm{J}$ and $\mathrm{Hu} \mathrm{R}$ : Inflammasome-independent NLRP3 is required for epithelialmesenchymal transition in colon cancer cells. Exp Cell Res 342: 184-192, 2016

18. Louis DN, Ohgaki H, Wiestler OD, Cavenee WK, Burger PC, Jouvet A, Scheithauer BW and Kleihues P: The 2007 WHO classification of tumours of the central nervous system. Acta Neuropathol 114: 97-109, 2007.

19. Kahlert UD, Nikkhah G and Maciaczyk J: Epithelial-tomesenchymal(-like) transition as a relevant molecular event in malignant gliomas. Cancer Lett 331: 131-138, 2013.

20. Ling G, Ji Q, Ye W, Ma D and Wang Y: Epithelial-mesenchymal transition regulated by $\mathrm{p} 38 / \mathrm{MAPK}$ signaling pathways participates in vasculogenic mimicry formation in SHG44 cells transfected with TGF- $\beta$ cDNA loaded lentivirus in vitro and in vivo. Int J Oncol 49: 2387-2398, 2016.

21. Zhuang Y, Peng H, Mastej V and Chen W; MicroRNA regulation of endothelial junction proteins and clinical consequence: MicroRNA regulation of endothelial junction proteins and clinical consequence. Mediators Inflamm 2016: 5078627, 2016.
22. Tang M, Zhao Y, Liu N, Chen E, Quan Z, Wu X and Luo C: Overexpression of HepaCAM inhibits bladder cancer cell proliferation and viability through the AKT/FoxO pathway. J Cancer Res Clin Oncol 143: 793-805, 2017.

23. Lim SY, Menzies AM and Rizos H: Mechanisms and strategies to overcome resistance to molecularly targeted therapy for melanoma. Cancer 123 (S11): 2118-2129, 2017.

24. Wei Q, Mu K, Li T, Zhang Y, Yang Z, Jia X, Zhao W, Huai W, Guo P and Han L: Deregulation of the NLRP3 inflammasome in hepatic parenchymal cells during liver cancer progression. Lab Invest 94: 52-62, 2014

25. Kong H, Wang Y, Zeng X, Wang Z, Wang $\mathrm{H}$ and Xie W: Differential expression of inflammasomes in lung cancer cell lines and tissues. Tumour Biol 36: 7501-7513, 2015.

26. Li Y, Li J, Li S, Li Y, Wang X, Liu B, Fu Q and Ma S: Curcumin attenuates glutamate neurotoxicity in the hippocampus by suppression of ER stress-associated TXNIP/NLRP3 inflammasome activation in a manner dependent on AMPK. Toxicol Appl Pharmacol 286: 53-63, 2015.

27. Allen IC, TeKippe EM, Woodford RM, Uronis JM, Holl EK, Rogers AB, Herfarth HH, Jobin C and Ting JP: The NLRP3 inflammasome functions as a negative regulator of tumorigenesis during colitis-associated cancer. J Exp Med 207: 1045-1056, 2010.

28. Wang Y, Kong H, Zeng X, Liu W, Wang Z, Yan X, Wang H and Xie W: Activation of NLRP3 inflammasome enhances the proliferation and migration of A549 lung cancer cells. Oncol Rep 35: 2053-2064, 2016

29. Munoz L, Yeung YT and Grewal T: Oncogenic Ras modulates p38 MAPK-mediated inflammatory cytokine production in glioblastoma cells. Cancer Biol Ther 17: 355-363, 2016.

30. Fathima Hurmath K, Ramaswamy P and Nandakumar DN: IL-1 $\beta$ microenvironment promotes proliferation, migration, and invasion of human glioma cells. Cell Biol Int 38: 1415-1422, 2014.

31. Sun W, Depping R and Jelkmann W: Interleukin-1 $\beta$ promotes hypoxia-induced apoptosis of glioblastoma cells by inhibiting hypoxia-inducible factor-1 mediated adrenomedullin production. Cell Death Dis 5: e1020, 2014.

32. Tarassishin L, Lim J, Weatherly DB, Angeletti RH and Lee SC: Interleukin-1-induced changes in the glioblastoma secretome suggest its role in tumor progression. J Proteomics 99: 152-168, 2014.

33. Tarassishin L, Casper D and Lee SC: Aberrant expression of interleukin-1 $\beta$ and inflammasome activation in human malignant gliomas. PLoS One 9: e103432, 2014.

34. Zheng X, Jiang F, Katakowski M, Zhang ZG, Lu QE and Chopp M: ADAM17 promotes breast cancer cell malignant phenotype through EGFR-PI3K-AKT activation. Cancer Biol Ther 8: 1045-1054, 2009.

35. Song H, Zhang Y, Liu N, Zhao S, Kong Y and Yuan L: miR-92a-3p exerts various effects in glioma and glioma stem-like cells specifically targeting CDH1/ $\beta$-catenin and Notch-1/Akt signaling pathways. Int J Mol Sci 17: E1799, 2016.

36. Li X, Wu C, Chen N, Gu H, Yen A, Cao L, Wang E and Wang L: $\mathrm{PI} 3 \mathrm{~K} / \mathrm{Akt} / \mathrm{mTOR}$ signaling pathway and targeted therapy for glioblastoma. Oncotarget 7: 33440-33450, 2016.

37. Mueller S, Phillips J, Onar-Thomas A, Romero E, Zheng S, Wiencke JK, McBride SM, Cowdrey C, Prados MD, Weiss WA, et al: PTEN promoter methylation and activation of the PI3K/Akt/ mTOR pathway in pediatric gliomas and influence on clinical outcome. Neuro-oncol 14: 1146-1152, 2012.

38. Moon SH, Kim DK, Cha Y, Jeon I, Song J and Park KS: PI3K/Akt and Stat 3 signaling regulated by PTEN control of the cancer stem cell population, proliferation and senescence in a glioblastoma cell line. Int J Oncol 42: 921-928, 2013.

39. Zhang F, Wang Y, Sun P, Wang ZQ, Wang DS, Zhang DS, Wang FH, Fu JH, Xu RH and Li YH: Fibrinogen promotes malignant biological tumor behavior involving epithelialmesenchymal transition via the $\mathrm{p}-\mathrm{AKT} / \mathrm{p}$-mTOR pathway in esophageal squamous cell carcinoma. J Cancer Res Clin Oncol 143: 2413-2424, 2017

40. Mizushina Y, Shirasuna K, Usui F, Karasawa T, Kawashima A, Kimura H, Kobayashi M, Komada T, Inoue Y, Mato N, et al: NLRP3 protein deficiency exacerbates hyperoxia-induced lethality through Stat3 protein signaling independent of interleukin-1ß. J Biol Chem 290: 5065-5077, 2015.

41. Morris EJ, Kawamura E, Gillespie JA, Balgi A, Kannan N, Muller WJ, Roberge M and Dedhar S: Stat3 regulates centrosome clustering in cancer cells via Stathmin/PLK1. Nat Commun 8: $15289,2017$. 
42. Cao YY, Yu J, Liu TT, Yang KX, Yang LY, Chen Q, Shi F, Hao JJ, Cai Y, Wang MR, et al: Plumbagin inhibits the proliferation and survival of esophageal cancer cells by blocking STAT3-PLK1-AKT signaling. Cell Death Dis 9: 17, 2018.

43. Saitoh M, Endo K, Furuya S, Minami M, Fukasawa A, Imamura T and Miyazawa K: STAT3 integrates cooperative Ras and TGF- $\beta$ signals that induce Snail expression. Oncogene 35: 1049-1057, 2016.

44. Lech M, Lorenz G, Kulkarni OP, Grosser MO, Stigrot N, Darisipudi MN, Günthner R, Wintergerst MW, Anz D, Susanti HE, et al: NLRP3 and ASC suppress lupus-like autoimmunity by driving the immunosuppressive effects of TGF- $\beta$ receptor signalling. Ann Rheum Dis 74: 2224-2235, 2015.

45. Xiong S, Cheng JC, Klausen C, Zhao J and Leung PC: TGF- $\beta 1$ stimulates migration of type II endometrial cancer cells by downregulating PTEN via activation of SMAD and ERK1/2 signaling pathways. Oncotarget 7: 61262-61272, 2016.
46. Eritja N, Felip I, Dosil MA, Vigezzi L, Mirantes C, Yeramian A, Navaridas R, Santacana M, Llobet-Navas D, Yoshimura A, et al: Smad3-PTEN regulatory loop controls proliferation and apoptotic responses to TGF-beta in mouse endometrium. Cell Death Differ 24: 1443-1458, 2017.

This work is licensed under a Creative Commons Attribution-NonCommercial-NoDerivatives 4.0 International (CC BY-NC-ND 4.0) License. 